\title{
Use of Game Systems of Scaling for the Improvement of GIS Productivity
}

\author{
Kirill Zhigalov ${ }^{1,2, *}$ \\ ${ }^{1}$ V.A. Trapeznikov institute of Control Science of Russian Academy of Sciences, 117997 Moscow, Russia \\ ${ }^{2}$ Moscow Technological Institute, 119334 Moscow, Russia
}

\begin{abstract}
The application of a game method of megatextures in GIS systems is considered in the article. The main attention is paid to the method usage not only in image display, but also in relief scaling and 3D models. The application of the method of relief megatextures will allow to significantly increase the image quality of a relief and the quality of the calculations of volumes and distances almost without losing system productivity. It is possible to use this technique in any modern GIS, that will allow to process much more basic data.
\end{abstract}

\section{Introduction}

Due to the recently increased data stream, the existing displaying mechanisms in the modern GIS systems don't cope with the task of high-quality display. In this connection, GIS operation is a constant compromise of minimum sufficient volume of basic data. Nevertheless, if not all the data participate in the processing, it will badly affect both mathematical and visual parameters. The companies, which are engaged in game development, solved this problem long ago. We will try to review briefly their idea with regard to GIS systems.

\section{Textures' Optimization}

Nowdays, game systems use so-called units of megatextures for image quality improvement, they allow to break textures into units and to use different permissions for their displaying, depending on the remoteness of an object, to which they belong, from the camera. As the aerial photography, used in GIS systems, have a high-resolution-, they occupy a considerable part of a video card memory in case of their loading, It may lead to failures of displaying them or to essential slowdown of system operation in general (see Tab. 1).

It was defined by practical considerations, that it is reasonable to use three-fold scaling. In other words, the area located as close as possible to the camera (in our case it was a square of 1 by 1 kilometer) boots using the maximum possible resolution, the next one - using the resolution of $70 \%$. And all the remaining - using the resolution of $30 \%$ (see a Fig. 1) [1, 2].
Table 1. Dependence of the speed of application opening with a texture from its volume.

\begin{tabular}{|l|l|l|l|l|l|}
\hline \multirow{2}{*}{$\begin{array}{l}\text { Video } \\
\text { card } \\
\text { memory } \\
\text { size }\end{array}$} & \multicolumn{4}{|c|}{ Speed of application opening with a texture } \\
\cline { 2 - 6 } & $0,5 \mathrm{~Gb}$ & $1 \mathrm{~Gb}$ & $2 \mathrm{~Gb}$ & $4 \mathrm{~Gb}$ & $8 \mathrm{~Gb}$ \\
\hline $0,5 \mathrm{~Gb}$ & $30 \mathrm{sec}$ & $5 \mathrm{~min}$ & $\begin{array}{l}\text { could } \\
\text { not run }\end{array}$ & $\begin{array}{l}\text { could } \\
\text { not run }\end{array}$ & $\begin{array}{l}\text { could } \\
\text { not run }\end{array}$ \\
\hline $1 \mathrm{~Gb}$ & $15 \mathrm{sec}$ & $1 \mathrm{~min}$ & $5 \mathrm{~min}$ & $\begin{array}{l}\text { could } \\
\text { not run }\end{array}$ & $\begin{array}{l}\text { could } \\
\text { not run }\end{array}$ \\
\hline $2 \mathrm{~Gb}$ & $15 \mathrm{sec}$ & $\begin{array}{l}30 \\
\mathrm{sec}\end{array}$ & $1 \mathrm{~min}$ & 5 min & $\begin{array}{l}\text { could } \\
\text { not run }\end{array}$ \\
\hline
\end{tabular}

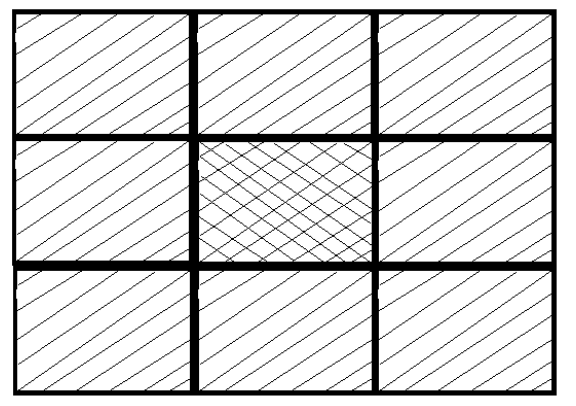

Fig. 1. Scheme of image scaling when using megatextures when a camera is placed in the middle of a map.

Such configuration allows to release video card resources on average for $60 \%$, that positively influences the speed of the GIS 3D displaying in real time. At the same time, the general quality of displaying remains at rather high level (see Fig. 2) [2].

Nevertheless, this technology has also disadvantages [2]: (1) More space on the server or at the workstation for storage of additional copies of textures (It was

Corresponding author: kshakalov@,mail.ru 
calculated that, the space is required twice more on average) is required; (2) The program needs time for the conversion of a GIS image or of a texture before displaying them.

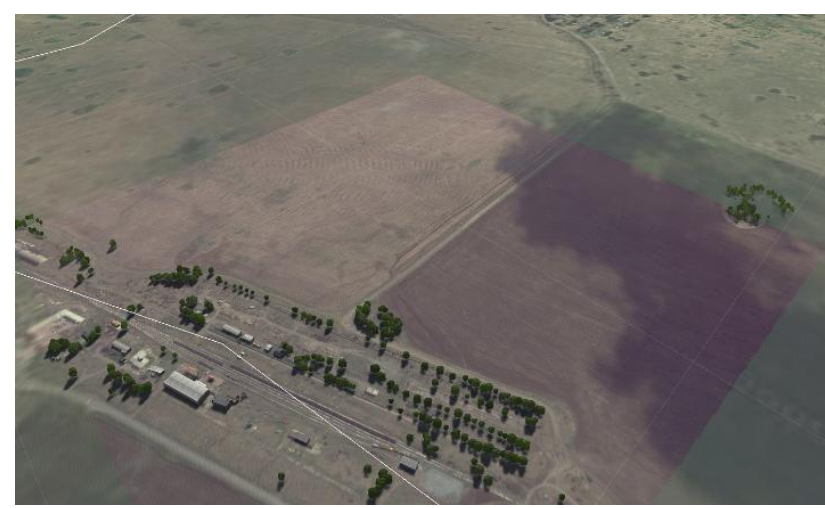

Fig. 2. An example of displaying of megatextures in GIS.

\section{Optimization of surface displaying}

Similar kinds of megatexture system can also be used in case of surface displaying. The surface is built on the points, consisting of 3 coordinates $(\mathrm{X}, \mathrm{Y}, \mathrm{Z})$. In case of large areas of GIS covering (for example, 20 by 20 kilometers) and large scale (for example 1:5000) there may be 2-3 000000 of points. At the same time, single displaying of a surface consisting of more than 500000 points significantly slows down the system (system response time is more than 1 second) [3].

According to the conducted research, it is necessary to discharge points in the ratio 1:4 (see Fig. 3) for the solution of the problem of speeding up the displaying.

There is a number of questions while using this method:

- Absence of a possibility of real-time computings;

- A possibility of appearance of "holes" in places of transition of the complete model into the discharged one of a surface.

Both of these issues are resolved by analogy with megatextures by the preliminary surface modeling with the maximum quantity of points. Then the surface is discharged and a surface with the thinned-out points is created. Further both surfaces are cut on squares (for example, equal to 1 on 1 sq. kilometer). In case of GIS displaying the program builds by default the surface discharged, and in the places as close as possible to the camera squares of a complete surface are displayed.

At the same time, the system does all calculations on a complete surface that allows saving accuracy at the original level. One of the disadvantages of the system displaying is the impossibility to edit surface in real time as it is connected with a large volume of calculations.

Nevertheless, such system is quite efficient for the majority of tasks without editing a surface.

According to the carried-out tests, the system allows to save up to $40 \%$ of the CPUs resources, $60 \%$ of resources of a RAM and to $35 \%$ of resources of the video card in case of the area of GIS spanning in 90 sq. kilometers and quantity of points of a surface equal 3 500000 .
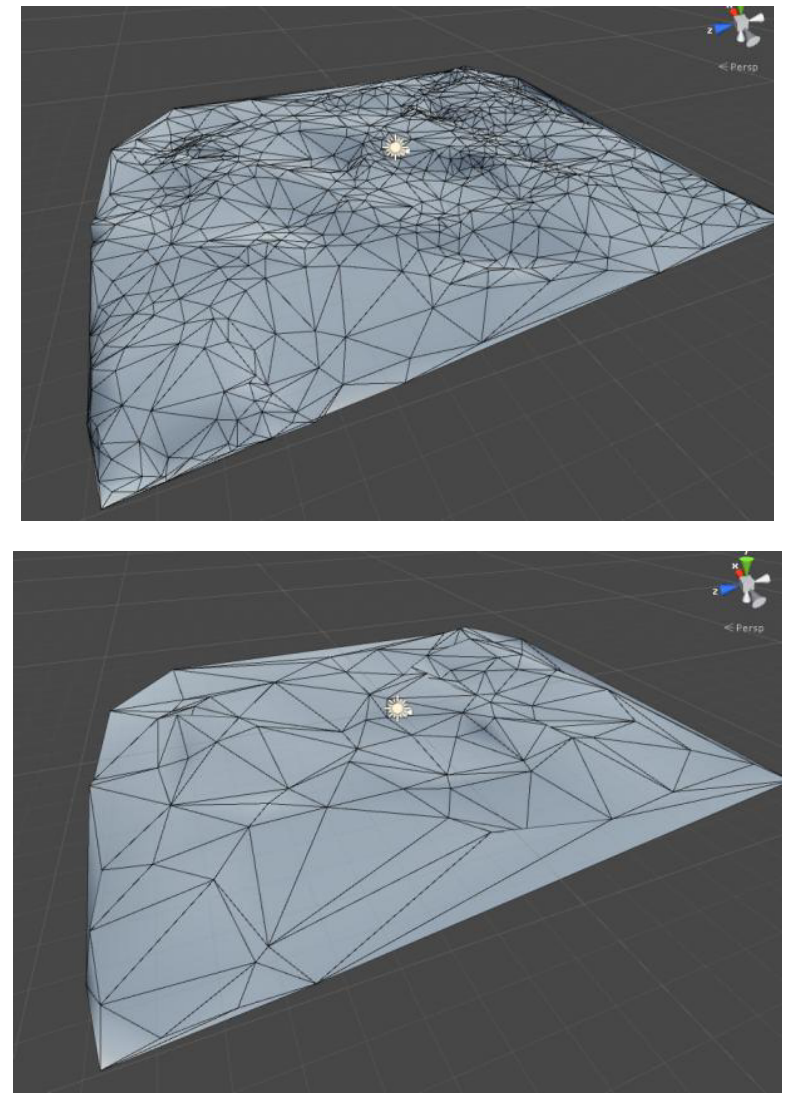

Fig 3. An example of displaying of the complete and discharged surface.

\section{Conclusion}

According to the conducted researches volumes of the data, displayed in GIS, permanently grow. Nevertheless, resources of users' computers are restricted. Besides, on average users update a computer once in 5-7 years. In this connection, vendors of GIS systems have a problem of optimization of geographic information systems themselves for the upcoming tasks. Megatextures and a megarelief can be one of the decisions. This combination of solutions can save up to $50 \%$ of resources of user machines or servers, that allows to re-distribute them on improving of systems of visualization.

\section{References}

1. A. Bhardwaja, L. Samb et al. Remote Sensing of Environment, 175, 196-204 (2016)

2. K. Zhigalov, ITM Web of Conferences, 6, 03018 (2016)

3. In-Ae Yeoa, Jurng-Jae Yee, Automation in Construction, 71, 398-413(2016) 